\title{
Neoliberalismo e Percepções da Importância do Turismo em Moçambique: Uma Discussão Crítica e Prática
}

\section{Neoliberalism and Perceptions of the Importance of Tourism in Mozambique: A Critical and Practical Discussion}

\author{
Fidel Terenciano (TERENCIANO, F.) ${ }^{*}$ \\ Cornélio Raimundo Mucache (MUCACHE, C. R.) \\ António Salião (SALIÃO, A.) ${ }^{* * *}$
}

\begin{abstract}
RESUMO - Neste estudo se analisa o turismo em Moçambique e a influência do neoliberalismo na construção dos saberes políticos para gestão da actividade turística per si. Desde os tempos, esta actividade sempre foi associada ao processo de geração de renda e empregabilidade, e que contribui para o desenvolvimento das localidades a qual se opera, mas este ethos é interlaçado pela visão pragmática do capitalismo e suas metamorfoses. Metodologicamente, o artigo foi desenvolvido seguindo a abordagem uni-nível, isto é, construção de variações considerando a percepção neoliberal do turismo em Moçambique, seguindo de uma pesquisa bibliografia e documental sobre os dados do turismo e as dinâmicas desta actividade em Moçambicano. Os resultados constataram que apesar das politicas do turismo em Moçambique possuir um viés economicista, contribui também no desenvolvimento da comunidade, produzindo renda e emprego nos locais turísticos. Alias, verifica-se a necessidade de trabalho conjunto entre os diversos operadores, com vista a dar reposta as exigências do mercado, e considerar a dimensão conservação e coordenação de políticas que permite a diversificação da base produtiva que inclua o turismo.
\end{abstract}

Palavras-Chave: Turismo; Neoliberalismo; Desenvolvimento; Moçambique.

ABSTRACT - This study analyzes the effects of tourism in Mozambique and the influence of neoliberalism in the reconstruction of knowledge and political projects for the management of tourism. Since the times, this activity has always been associated with the process of income generation and employability, which contributes to the

\footnotetext{
* Graduação em Ciência Política na Universidade Eduardo Mondlane - Moçambique. Mestre em Ciência Política e Políticas Públicas - UFPA e Doutorando em Ciência Política na UFSCar e pesquisador no Centro de Estudos de Partidos Políticos da UFSCar/CNPq - Brasil. Professor e Investigador na Universidade Católica de Moçambique - Faculdade de Gestão de Turismo e Informática - FGTI - Pemba. Endereço físico para correspondência: Rua 7 de Setembro, 1458 - São Carlos - SP - Brasil. CEP: 13560180. Email: fideldeanarosa@gmail.com / fidelt@ufscar.br

** Graduação em Teologia pelo Instituto São Paulo de Estudos Superiores - ITESP. Graduado em Filosofia pela Universidade São Tomás de Moçambique. Doutorando em Educação, com ênfase em História e Filosofia da Educação - UNIMEP/Brasil. Professor da Rede Estadual de Educação - São Paulo. Endereço físico para correspondência: Rua Conselheiro Cotegipe, 951, Belenzinho. São Paulo - Brasil. CEP: 03058-000. E-mail: cornemucache@yahoo.com.br

*** Graduação em Economia e Gestão na Universidade Católica de Moçambique. Professor na Universidade Católica de Moçambique - FGTI - Pemba. Estudante no curso de doutorado em Economia na Universidade Católica de Porto - Bussines School. Endereço físico para correspondência: Bairro Eduardo Mondlane, 27. CEP: 044126 - Cidade de Pemba - Moçambique. E-mail: ansaliao@gmail.com / asaliao@ucm.ac.mz
} 
development of the localities to which it operates, but this ethos is intertwined by the pragmatic view of capitalism and its metamorphoses. Methodologically, the article was developed following the uni-level approach, that is, construction of variations considering the neoliberal perception of tourism in Mozambique, followed by a bibliographical and documentary research on tourism data and the dynamics of this activity in Mozambican. The results show that although tourism policies in Mozambique have an economic bias, it also contributes to the development of the community, producing income and employment in tourist sites. In addition, there is a need to work together among the various operators in order to respond to market demands and to consider the policy conservation and coordination dimension that allows the diversification of the productive base that includes tourism.

Key words: Tourism; Neoliberalism; Development; Mozambique. 


\section{INTRODUÇÃO ${ }^{1}$}

O artigo objectiva fazer a discussão crítica sobre o neoliberalismo e seus impactos nas políticas de turismo e na dinâmica cotidiana dos moçambicanos. Constatou-se na construção do trabalho que no contexto do neoliberalismo, o Estado ao invés de contribuir para equalizar os benefícios socioeconômicos, prioriza a promoção das actividades econômicas desenvolvidas pelos atores hegemônicos (turistas e sector empresarial), enquanto que a coletividade se torna cada vez mais subordinada às determinações do mercado turístico.

A pesquisa perpassa pelas fronteiras do entendimento do papel do Estado moçambicano no contexto do capitalismo e do neoliberalismo, buscando entender de que forma a intervenção estatal repercute nas comunidades e contribui para a segregação sócio-espacial existente nas localidades onde se encontram "o tesouro turístico a ser consumido". Pois não há esforços para implantação de políticas alternativas e (in) ou (ex) clusivas de turismo. Neste sentido cabe este desdobramento: quem são os sujeitos "turísticos"? Qual é o lugar social e de fala desses sujeitos? De que maneira o turismo é compreendido em Moçambique? É simplesmente un tour de force (um passeio de imaginação) da dimensão estética das paisagens e texturas da natureza? Portanto a hipótese é de que o neoliberalismo, a expressão actual do ethos capitalista deturpou o conceito de turismo, reduzindo simplesmente ao desenvolvimento econômico, sobretudo nos locais a qual a actividade turística se desenvolve com maior lucidez (HARVEY, 2008... itálico dos autores).

Nesta esteira, a política de turismo em Moçambique possui uma metafísica empresarial. Aliás, nem sempre quando se fala de uma política de turismo se refere da descentralização do modo de consumo do turismo, primeiramente para os moçambicanos, mas sim, quanto vale o turismo para a economia? Portanto, esse é um problema ecossocial, que na visão dos autores precisa ser reflectido quando se trata de uma política do turismo no actual contexto de globalização excludente.

\footnotetext{
${ }^{1}$ Publicado no idioma português de Moçambique.
} 


\section{OPÇÕES METODOLÓGICAS}

Esta parte do artigo, objectiva desenvolver um conjunto de elementos explicativos relativos aos procedimentos e técnicas empregues para o desenvolvimento do estudo. A priori tratou-se de um estudo teórico, e ensaio marcadamente de revisão e pesquisa documental. Dos amplos documentos, seguem relatórios de estudos, de políticas públicas sobre turismo em Moçambique. Estes documentos permitiram o desenvolvimento das fases subsequentes deste artigo.

\subsection{MATERIAL E MÉTODOS}

O presente artigo foi realizado através de pesquisa bibliográfica em livros e revistas especializadas na matéria e discussões sobre turismo e suas amplas fissuras. Através desta pesquisa, foi possível fazer um levantamento e revisão da literatura existente para a elaboração conceitual, teórica e discussão empírica do artigo.

Como sugere Prodanov e Freitas (2009), a metodologia é a aplicação de procedimentos e técnicas que devem ser observadas para construção do conhecimento, e por via disso, o processo de materialização dos objectivos deste artigo seguiram uma abordagem qualitativa, isto é, uma intenção clara de revisar os principais debates sobre o turismo em Moçambique, sem se atear a demonstrações estatísticas ou quantitativas dos debates ao longo do artigo. Per si, Richardson (1999) sugere que a metodologia qualitativa permite não só descrever a complexidade de determinado problema, mas também sua análise e interação de certas variáveis, do mesmo modo, compreendendo e classificando o processos dinâmicos vividos por grupos sociais, tanto quanto de Moçambique, ao que se refere o turismo. Como tal, o processo de efetivação destes métodos seguiu um roteiro, desde a pesquisa bibliográfica e documental, até o processo de interpretação e atribuição de significações.

A pesquisa documental seguiu uma análise mais holística sobre os principais piriplos que regimentam a actividade turística, tais como documentos de instituições de tutela sejam públicas ou privadas e relatórios e planos publicados, como o Plano Estratégico de desenvolvimento do Turismo de Moçambique (2008); Lei do Ambiente, (2004), Lei de Turismo (2004), Política do Turismo (2003), Animação Turística (2007), 
Funcionamento de empreendimentos turísticos (2013), e outros similares, que facilitaram a exploração de principais pontos e elementos analíticos do turismo em Moçambique. Aliado a isso, um conjunto de relatórios que debruçam sobre as dinâmicas do turismo, descritas na literatura cinzenta (jornais, revistas tempo, entrevistas).

\section{RESULTADOS E DISCUSSÃO}

Os principais pontos de debate que são desenvolvidos nesta parte do trabalho, procuram ilustrar as dinâmicas funcionais do turismo e as principais visões (endógenas e exógenas) da estrutura do turismo em Moçambique. A ideia é indicar a importância do turismo e como a ele pode se repensar a sua construção social, económica e política do turismo em Moçambique, segue necessariamente nuances específicas e que devem ser ilustradas em sua dimensão contextual.

\subsection{CONTEXTO HISTÓRICO E A VISÃO ENDÓGENA DO TURISMO EM MOÇAMBIQUE: DA TEORIA A EMPIRIA}

Desde os tempos, o turismo constitui uma das actividades produtivas, que vem gerando emprego e renda e pode ser incluído entre os sectores chaves para o desenvolvimento de certas regiões ou localidades (CORREIA; MARIANI, 2009; BENI, 2007; ACIS, 2008; DOMINGOS, 2012; TORRES, 2005). Nestes termos, a actividade turística constitui uma área da economia mundial que ao longe do tempo vem se consolidando com um número cada vez maior de turistas e prestadores de serviço nesta área. Todavia, no contexto de Moçambique, existem problemáticas e limitam o fortalecimento deste sector, dos quais o artigo ao longo da sua descrição vai referenciando. Notavelmente, verifica-se que os agentes envolvidos com o turismo, que estão distribuídos no sector público e privado e nos territórios urbano e rural, existem diferenças e distanciamentos, como ilustra a Lei do Turismo (2004). Ora, essas diferenças podem ser observadas nas formas de gestão, nos objectivos que seguem e são 
traçados, nos interesses conflitantes e particulares de cada um e no entendimento de como é formado o sector de turismo no espaço rural e urbano.

Deste modo, os agentes que investem na actividade turística, sejam eles turistas ou prestadores de serviços e ou a sociedade, devem em parte, neste caso, no contexto de Moçambique, praticar uma consulta conjunta, compartilhar ou até cooperar entre si, com vista o aumento da produção e produtividade da actividade turística. O que se verifica em Moçambique, é uma desarticulação e ausência de efectivas ligações Inter sectoriais, que leva a falta de coesão inter e intra-organizacional, o que vai permitir como indica Correia e Mariani (2009), a um desequilibrado processo de integração entre os sectores operando na actividade turistica.

Recapitulando a conceptualização do turismo, e evidentemente assumindo a diversidade de pontos de vista formal e seguindo como padrão de referência as estatísticas internacionais sobre ela, como sustenta a Organização Mundial do Turismo - OMT, em 1994, que indica o turismo como:

[...] conjunto de actividades que as pessoas realizam durante suas viagens e estadas em lugares distintos de seu entorno habitual, por um período de tempo consecutivo inferior a um ano, com fins de lazer, negócios ou por outros motivos não relacionados ao exercício de alguma actividade remunerada no local visitado [...] (OMT, 1994, p. 31).

Doravante, Zimmermann (1996), Beni (2007), Correia e Mariani (2009), Mielke e Valente (2017) apreendem que o turismo deve ser subentendido como um fenómeno social, político, económico e cultural, isto é, antropo-socio-cultural e económico, que ao permitir um conjunto de actividades sejam elas formais ou informais (transporte, alojamento, recreação e outras), faz com que elas gerem outros efeitos sobre o meio ambiente (RUSCHMAN, 1999) no local onde se desenvolve a actividade turística.

Três elementos são chaves para uma percepção da actividade turística: o espaço físico, o tempo e o indivíduo (ZIMMERMANN, 1996; CORREIA; MARIANI, 2009). No entanto, estes elementos se apresentam como básicos que compõem a estrutura do turismo tanto em Moçambique e não só. Ora, neste processo, há um conjunto de factores económicos e não económicos que vão delinear a escolha dos destinos, a permanência no local escolhido, e os meios de transporte bem como o alojamento. 


\subsection{PERCEPÇÃO SOCIAL, POLITICA E ECONÔMICA DO TURISMO EM MOÇAMBIQUE}

Os processos e dinâmicas do funcionamento tanto das políticas, jurisprudência e questões culturais e seu impacto no funcionamento do turismo, devem ser considerados eixos chaves para desenvolvimento deste fenômeno 'turismo'. Beni (2007), por exemplo, indica que para o desenvolvimento harmonioso da actividade turística, são necessários: 1 - Espaço geográfico; 2 - A demanda; 3 - A oferta; 4 - As operadoras de mercado. Estes elementos corroboram um conjunto de diferentes factores relacionados e que se caracterizam como sistema, que deve evoluir em qualquer sociedade, época num sentido dinâmico. Em função disso, as actividades turísticas considerando a origem e o destino dos turistas, podem ser classificadas em: Turismo Doméstico (notavelmente os turistas que endogenamente visitam seu país. Seria o caso de um cidadão de Pemba, visitar as Bazaruto); Turismo Receptivo (não residentes provenientes de um determinado país. Isto é, Dinamarqueses visitando o arquipélago de Quilaleia). Turismo Emissor (Turistas de um país que visitam outro país). Da mesma forma, existe a combinação do turismo interior (doméstico e receptivo) nacional (doméstico emissor) turismo internacional (emissor e receptivo).

Numa dimensão longitudinal em Moçambique, o turismo representa um importante instrumento de transformação das sociedades, que pode promover a inclusão social, permitir oportunidades de emprego, novos investimentos, receitas e empreendedorismo local. Além disso, é uma actividade formal e que contribui para a economia mundial, e no caso de Moçambique e mundialmente uma das mais rentáveis e promissoras actividades em processo robusto de expansão no mundo (OMT, s.d.; CUNHA, 2013). Dados indicam que esta actividade, em 2001 constituiu uma "indústria" internacional importante, e dando uma contribuição em cerca de $4.2 \%$ do Produto Interno Bruto - PIB mundial e empregando $8.2 \%$ da população mundial economicamente activa, e a "África Sub Sahariana cresceu 7,5\% do emprego do qual boa parte era oriunda desta actividade" (UNCTAD, 2017; PLANO ESTRATÉGICO DE DESENVOLVIMENTO DE TURISMO, 2016-2025). No entanto, verifica-se que este crescimento, representa uma contribuição em cerca de $10,6 \%$ da força de trabalho 
global e $10,2 \%$ do produto nacional bruto mundial, além de gerar receitas no valor de 655 bilhões de dólares (MINTUR, 2006; JONES et al., 2007)..

Retrospectivamente, em Moçambique, o turismo era considerado um dos destinos turísticos em África, e este sector em particular sempre jogou um papel na sociedade como um todo, e jogava um papel importante na economia do país (PEDTM, 2004; GUMBE, 2006).

E a gestão eficiente e o processo de regulamentação da actividade em Moçambique ainda em tempo colonial começam na segunda metade dos anos 50, com o processo de criação dos primeiros centros de informação de turismo. Todavia, em 1962, se estabelecem as primeiras zonas de turismo e em 1972, era num número de 26. Mas o processo de delimitação das zonas turísticas era baseado em critérios subjectivos e tomando o consenso como o discurso adicional, e considerando a importância relativa das atracções de cada zona (PEDTM II - 2016-2025).

Ademais, Moçambique foi ponto de referência para amplos turistas de praia dos países da África Austral, e constituía espaço predileto para as férias de grande parte dos vizinhos da África do Sul. Dos elementos que podem ser elencados como motivadores, pode se ilustrar: as praias de águas límpidas, as ilhas, o mar quente, o povo, a pesca desportiva, os desportos aquático (MINISTÉRIO DO TURISMO, 2010; BELOTI, 2012).

Post independência, a actividade turística foi também caracterizada por uma baixa em termos de níveis de procura, devido às dinâmicas políticas, econômicas e sociais da região e, sobretudo a guerra dos 16 anos que assolavam Moçambique, aliado a falta de técnicos especializados para planificar e fazer gestão do sector e conflito que destruiu as infraestruturas turísticas, as vias de acesso, comunicação e transporte.Ora, Jones et al. (2007), Gumbe (2006) evidenciam que nos anos 1980 e princípios de 1990, o turismo na sua dimensão externa constitui principalmente na estadia de missões de cooperação internacional de Paz. Por fim, havia uma enorme digressão de assegurar que a comunicação e imagem do País como destino turístico deveriam ser transmitidas de forma eficiente e eficaz no mercado doméstico, regional e internacional e reflicta os valores que norteiam o turismo em Moçambique (MINISTÉRIO DO TURISMO, 2010; BELOTI, 2012). 
Em termos de contribuições, o turismo em Moçambique desde 2010, gerou receita em torno de 17.69 bilhões de meticais, representando $6,2 \%$ da renda nacional total e 5,6\% do PIB, e a contribuição do turismo no emprego formal e informal estimouse em 45.350 postos de trabalho até 2012 (PEDTM, 2016-2025).

Na dimensão da gestão estratégica em retrospectiva, verificou-se que a Política do Turismo e a Estratégia da sua Implementação, a qual o processo de aprovação ocorreu em Abril de 2003, apresentava-se com objectivo de substituir a Política e Estratégia Nacional do Turismo (1995), ou seja, o novo Plano Estratégico de Desenvolvimento do Turismo de Moçambique (2003), procurou assegurar, seguir e colocar em apenas único documento, as directrizes, linhas orientadoras e perspectivas futuras do desenvolvimento do turismo num plano estratégico de 1995 (Estratégia para o Desenvolvimento de Turismo em Moçambique: 1995-1999), ao do plano de desenvolvimento estratégico para o turismo nas zonas litorais - 1997 (Um Quadro de Planificação para o Desenvolvimento de Turismo Regional em Moçambique) e a nova abordagem da Política do Turismo em relação à conjugação do "binómio" produtomercado e as áreas prioritárias para o desenvolvimento do turismo, integrando as áreas de conservação (PEDTM, 2004-2013, p. 9).

Neste mote, em Moçambique, existe a percepção de que o turismo é uma actividade socioeconómica e que alicerça a economia Moçambicana frágil num país em via de desenvolvimento. Por isso, o contínuo investimento cada vez mais para atrair turistas, que vem se constituindo uma prioridade dos planos e políticas do desenvolvimento da actividade do turismo (TORRES, 2005; ACIS, 2008; DOMINGOS, 2012; DANIEL, 2013). Em razão disso, em 1995, o governo de Moçambique, cria o Ministério especifico e define o turismo como uma área prioritária para maximizar a entrada de divisa ao país e geração cada vez mais de emprego e renda, com vista a sua contribuição no desenvolvimento do país (DANIEL, 2013). Nisso, tratou-se como Macamo (s./d.) considera, de uma nova era do turismo em Moçambique.

Em 2003, o governo de Moçambique, aprova a política do turismo e estratégias de sua implementação, que trouxe como se sucedeu em 1995 (Estratégia para o Desenvolvimento de Turismo em Moçambique: 1995-1999), onde se apresentavam às linhas mestres para o desenvolvimento harmonioso da actividade turística. Desde então, são ilustradas algumas vantagens, como o desempenho positivo da economia de 
Moçambique nas últimas duas décadas (1999-2013). Aqui devem ser consideradas as taxas de crescimento do PIB que se tem situado acima de 6\% anuais (PEDTM, 2004; GUMBE, 2006).

É possível anotar um conjunto de desafios previstos no Plano estratégico do desenvolvimento do turismo (2016-2025), dos quais, afiguram-se 4 pontos, denominados de ADIC, os quais, 1) Acesso (altos custos de passagens aéreas e um regime de vistos limitativo), 2) Demanda/Procura (preços altos, má imagem e um fraco posicionamento de mercado), 3) Investimento (preocupações com o regime de posse da terra, altos níveis de importação, desenvolvimento limitado de atractivos naturais e culturais, poucas estâncias turísticas de alta qualidade) e, 4) Competências (pouca mãode-obra qualificada na indústria de hospitalidade, lacunas em competências e conhecimentos nas instituições do sector público aos níveis central e provincial do turismo e cooperação fraca entre os sectores público e privado) (PEDTM, 2016-2025).

\section{UM ESCOPO DO TURISMO COMO UMA OPORTUNIDADE PARA OS EXCLUÍDOS}

Considerações iniciais neste ponto indicam que a dimensão teórica e prática do neoliberalismo e da acumulação flexível que se sucede nos últimos tempos, leva consigo um grande número de elementos nefastos à sociedade, das quais uma enorme massa de desempregados, fenómeno que atinge todos os países periféricos, o que leva a produção de um processo autodestrutivo, gerando uma imensa sociedade de excluídos (CUNHA, 1997; LAGE, 2001; BARBOSA, 2005).

\subsection{TURISMO, UM ESPAÇO DE CONSUMO E DE CONFLITOS}

Neste trabalho, o espaço é entendido como sendo o principal objecto de consumo do turismo e materializa-se por meio dos objectos e acções como enfatizado por Milton Santos (2001); sendo assim, o espaço se recria e se reproduz constantemente nos lugares com potencial turístico. A partir da análise criteriosa dos desdobramentos das relações capitalistas e de poder advindas dos processos de produção dos espaços em 
questão, bem como, com base nas perspectivas da população residente acerca do crescimento da actividade turística e sua inserção no processo de desenvolvimento da actividade, pode-se chegar a algumas conclusões e reflectir sobre o modelo de turismo que o Estado moçambicano adotou para o desenvolvimento da actividade em âmbito nacional e seus rebatimentos no território onde se encontram "o turismo a ser consumido". Ao falar de planejamento turístico, considerou-se a importância das políticas de turismo para a construção de territórios como indicado acima, pois esta abordagem embasa e fundamenta as questões relacionadas à ocupação, à ordenação e à transformação do espaço apropriado pela actividade turística conforme relata Cruz (2001, p. 22):

[...] A transformação do espaço em produto turístico requer uma crescente racionalidade devido à competitividade entre produtos turísticos, que se dá, hoje, em escala global. Essas racionalidades e competitividade, que afetam a organização de todos os setores produtivos, como forma de adequação e sobrevivência a um mercado globalizado, fazem do planejamento territorial uma condição do sucesso de planos e políticas sectoriais[...].

A autora complementa seu pensamento afirmando que: o planejamento territorial se faz necessário para reorganização do lugar e para a elaboração de políticas setoriais (CRUZ, 2001, p. 22). Sendo que o turismo é actividade produtiva moderna que reproduz a organização desigual e combinada dos territórios capitalistas, e absorvido com maneiras diferenciadas pelas culturas e modos de produção locais.

No âmbito da nova dinâmica da acumulação capitalista, responde às crises globais e ampliadas do capital mundial, submetendo diretamente o Estado em favor do mercado, embora, e aos poucos, a sociedade civil de vários lugares descubra estratégias de beneficiar-se economicamente com ele, ou a partir dele. Como serviço de suporte à recuperação do trabalho humano, possibilita o avanço da exploração do trabalho industrial, comercial e financeiro, nos diversos mercados internacionais relacionados à actividade turistica. É o lazer de viagem, elitizado, transformado em mercadoria, invenção da sociedade de consumo. Forja respostas às necessidades humanas, mas atende especialmente ao capital. Fenômeno próprio das classes ricas que podem comprar lazer, o turismo atinge todos os continentes e a muitos lugares periféricos. Estendeu seu raio de acção aos lugares tidos como subdesenvolvidos e às classes pobres, que passaram não a usufruir, mas a produzir serviços turísticos, pois a injustiça 
social e a desigualdade não foram eliminadas, e são próprias do capitalismo (FURTADO, 1998; CRUZ, 2001; CORIOLANO, 2003; 2006). Enquanto prática social é também econômica, política, cultural e educativa, envolvendo relações sociais e de poder entre residentes e turistas, produtores e consumidores.

Doravante, se não é menos verdade que o turismo é produto simultâneo do ócio, isto é, se não é mais verdade que ele é o produto do modo de viver contemporâneo, cujos serviços criam formas confortáveis e prazerosas de viver, restritas a poucos, então não é pouco verdade que é possível constatar logísticas globais sob o comando de corporações e bancos internacionais que se sobrepõem à autonomia dos governos redirecionando suas ações para atender interesses globais, embora com especificidades regionais. A riqueza do turismo está na diversidade de caminhos para sua produção e apreensão, nos conflitos e possibilidades de entendimento desse fenômeno (CHESNAIS, 1996; CORIOLANO, 2006; SILVA; MANTOVANELI; SAMPAIO, 2014).

Operadores turísticos alocam seus investimentos e retiram mais-valia dos espaços, do trabalho humano. Passam a ser meios e produtos das relações de força e de poder produzidas para e pelo o turismo, que se estabelecem de forma contraditória e articulada entre o lugar, a nação e o mundo. O turismo materializa-se na lógica da diferenciação histórica e geográfica dos lugares e das regiões (CORIOLANO, 2003; 2006). É pertinente ao local tanto quanto ao mundial, pois domina as relações sociais históricas em função de mudanças e reestruturação dos espaços, aproveitando os recursos locais. Transfere o valor dos patrimónios culturais, das cidades, e dos lugares da população local para os turistas, enquanto objeto do olhar, do prazer e de desejo. Em função do turismo e do consumo dos espaços são produzidas diversas formas estruturais de paisagens e de negócios.

No tempo onde os processos históricos seriam inoperantes, a técnica utilizada proporciona agilidade e capacidade de organização territorial, sendo que para cada modalidade de turismo existe uma demanda espacial. Aproveitam-se áreas como reservas naturais, litorais, áreas urbanas e rurais, cidades históricas. Com o turismo, novos processos concentram ou distribuem renda, aumentam ou diminuem as formas de exploração dos trabalhadores, além de entrada ou fuga das divisas. Requer, como toda actividade capitalista, controle governamental e, sobretudo, participação da sociedade. 
Os equipamentos turísticos (hotéis, restaurantes, agências de viagens, de comunicação) e os ambientes de lazer servem de suporte à mobilização da mão-de-obra globalizada, afinal estão a serviço da reprodução do capital. Mas, a lógica não é tão perfeita como querem os neoliberais (PEARCE, 1991; SILVEIRA, 2002; CORIOLANO, 2006). Sob concorrência oligopolista, os investidores sofrem restrições de mega-operadoras internacionais, em função dos altos níveis de concentração e de integração de grandes conglomerados actuantes nos principais mercados emissores.

Criam-se, muitas vezes, barreiras à sobrevivência e entrada de novas operadoras e de pequenos destinos turísticos, que lhe permite produzir espaços estandardizados e controlados pelas redes mercantis transnacionais que dificultam o crescimento das empresas locais e regionais (PEARCE, 1991; CORIOLANO, 2006; SILVA; MANTOVANELI; SAMPAIO, 2014). Enquanto negócio visa lucros e desenvolvê-lo implica continuar a distribuição injusta da riqueza. Portanto, produz contradição ao se propor ao desenvolvimento local, preservar lugares, e proteger as culturas, obtendo, ao contrário, a transformação do espaço em mercadoria, massificação das culturas; atendendo as necessidades dos que vem de fora em detrimento dos que ali habitam.

\subsection{EXPECTATIVAS DO TURISMO E CONTROVERSAS DA REDUÇÃO DA POBREZA NAS ZONAS TURÍSTICAS}

Apesar da expectativa principal do turismo ser o lucro, e produzir e distribuir riqueza e renda, também cria oportunidades de ganhos para os trabalhadores e os lugares mais pobres. Assim, na contradição de que destrói e beneficia, o turismo pode ser visto positivamente tal como na perspectiva da tese, que ao incorporar a antítese, o seu "contraponto", transforma-se em síntese, ponto e novamente contraposição da posição, marcando o processo evolutivo da sociedade. Como positivo, trouxe, em alguns casos, a descoberta comunitária de outro turismo possível. Diferindo na forma como o turismo é explorado, ou como se dão as relações sociais de produção, que determinam mais ou menos exploração e concentração da renda (CORIOLANO, 2003).

As explorações exacerbadas nas relações de trabalho associam-se às relações mais flexíveis e adaptadas aos interesses das comunidades locais. Assim, executivos de resorts ambulantes, vendedores de souvenir (lembranças) e artesanatos são igualmente 
trabalhadores no turismo. Ao mesmo tempo em que a tendência de acumulação cresce na maioria dos lugares e na maior parte dos negócios turísticos, inclusive em Moçambique nas regiões litorâneas, emergem ricas experiências voltadas para menor exploração do trabalho, com melhores ganhos para os trabalhadores, além dos capitalistas, distribuindo melhor os resultados do trabalho social e fazendo valer os valores comunitários (PEARCE, 1991; RODRIGUES, 1997; CORIOLANO, 2006).

O modelo fordista massificou a cultura, a escola, a comunicação, também tornou massivo o turismo, cuja superação requereu a estratégia de fusões/aquisições, formação de conglomerados e de oligopólios dominantes, organizando a produção de forma flexível quanto ao trabalho e aos lugares. A crise do turismo fordista, porém, produziu o turismo flexível, voltado às individualidades, com alto nível de qualidade, profissionalismo e competência, e de altos custos, que seriam reduzidos quando adaptados às condições comunitárias, locais e regionais.

Do turismo global, elitizado e de resorts, emergiu o turismo local e alternativo, voltando-se para os interesses dos residentes, das pequenas pousadas, da valorização e manutenção da identidade local, mesmo que em processo simultâneo de resistência e solidariedade. Nesse processo seletivo de lugares para o turismo, novas contradições emergem, sendo mais comuns de usos e posse pela terra, e por oportunidades de trabalho. Do conflito, porém surge o turismo alternativo, aquele desenvolvido a partir das comunidades e pelas comunidades, bem como os das favelas, dos índios, dos acampamentos dos sem-terra, ou seja, de diversos grupos de excluídos (RODRIGUES, 1997; SILVA; MANTOVANELI e SAMPAIO, 2014). Todos os incluídos na mesma sociedade, no modo de produzir, mudando na forma como cada classe ou grupo se incluem, e como os níveis de conflitos produzem resistências ou não. Não há como afastar a análise do turismo da valorização do espaço e (ou) do mundo da produção e das contradições do modelo produtivo vigente, mas se podem obter resultados menos desiguais.

Os territórios turísticos passam, a um só tempo, por serem dominados (pelo capital) e apropriados (pelos interesses locais e dos trabalhadores). Os lugares além de pertencerem às estratégias do capital, do espetáculo e do embevecimento dos visitantes são susceptíveis as resistências dos residentes, apesar de nem todos participarem da luta. A maioria da população local, alienada que está pelo consumo, adapta-se ao sistema de 
produção capitalista convencional. O turismo é uma prática social que causa divisão interna nas comunidades, mas que demanda tempo para se transformar e obter resultados mais genéricos e sustentados (RODRIGUES, 1997). O discurso sobre o turismo é situado como opção para o desenvolvimento dos países, estados e municípios. Mas, na prática é uma super-estimação de seu desempenho, criando falsas expectativas, sem possibilidades de solução aos problemas sociais e ambientais existentes: não desenvolveu as regiões pobres, nem distribuiu a riqueza do País, além de não consolidar territórios, apenas organizar outros comparativamente. Acrescentou problemas onde foi tratado como política para atender somente a acumulação capitalista em detrimento das necessidades básicas dos trabalhadores locais. Transformou o espaço local em mercadoria global, desvalorizando o uso pela troca. As práticas sociais e políticas dos governos e dos grandes empresários primeiro conflitaram, depois coincidiram com as das comunidades e dos pequenos empreendedores.

Os focos de interesses específicos, a princípio divergentes - para os primeiros, o centro é a acumulação de capital e para os outros o enfoque é humanista - foram redirecionados para a solidariedade entre povos e lugares. É certo que na maioria dos lugares e territórios isto não é verdadeiro, mas a minoria mostrou que é possível e viável atender a interesses múltiplos. Idéias dominantes foram divulgadas até a formação de um discurso coletivo e quase todos os lugares passaram a afirmar ser o turismo gerador de emprego e renda. Constatou-se na prática, entretanto, que o discurso, de que todos ganham com o turismo, é superficial, pois mascara contradições e as diversas formas de exploração do trabalho, às vezes acirram as contradições entre o capital e o trabalho.

Algumas províncias no território moçambicano, vêm servindo como laboratório dessa dialética expressa nos discursos e práticas sobre o turismo, que opõe a percepção de mundo oficial e de mercado a aquela visão humanista e comunitária, conforme evidencia Coriolano (2003). Os governos propalam o discurso do mercado neoliberal, ao afirmar ser o turismo o caminho para o desenvolvimento; de que é o caminho certo, pois não há outro; e que os obstáculos serão vencidos; omitindo-se da missão com que foi criado, de regular o mercado. $\mathrm{O}$ que se esperava do Estado democrático era a interlocução das críticas, sem ceder, facilmente, aos pontos de vistas da classe dominante. 
Ao incorporar em seus discursos a idéia de comunidade e de inclusão social, o faz para se legitimar, mais que isso, para cooptar os movimentos e as resistências sociais, posicionando-se pelas minorias dominantes, ao contrário do que se esperava de ficar a favor da maioria excluída. As sociedades sem capacidade crítica para perceber a falácia do discurso governamental submeteram-se a ação estatal de construção de uma forma de turismo segregado, aquele que impede o turista de conhecer de fato o local que visita. Estados neoliberais se comprometem com o turismo internacional, esperando a entrada de divisas, sem verificar seus resultados sobre as "exclusões sociais", pois, na prática, as formas de se obter emprego e renda que garantam a grande maioria da população são poucas. Assim, de acordo com Coriolano (2003; 2006), muitos acreditaram no discurso da atividade ser introduzida nos países periféricos como alternativa de oferta de emprego e renda, e isso virou um mito. Aqueles que ainda não se inseriram nos roteiros lutam para sua inclusão. O planejamento, a administração, as políticas e gestões tão solicitadas no turismo não foram suficientes para superar as crises (CORIOLANO, 2003; 2006).

Afinal, o cerne da questão não está nessas ausências, mas nos conteúdos desses instrumentos, que são o próprio conteúdo das crises, seja no turismo ou outro setor da sociedade. É preciso superar os problemas das territorialidades turísticas antes de resolver as questões da gestão. Portanto, o caos não está nele próprio, mas no conteúdo que se deu a ele (RODRIGUES, 1997; CORIOLANO, 2006). As práticas da sociedade civil organizada e das comunidades tomaram duas direções distintas: daqueles que não acreditando no turismo, por acharem superestimadas as possibilidades de extraordinários ganhos pelo setor, e os que acreditaram e buscaram-no como perspectiva de desenvolvimento e solução para o lugar.

Mas, o que se constatou, foi que o turismo não é diferente de nenhuma actividade capitalista, não é maldição nem benção; é resultado das práticas políticas dos discursos hegemônicos e dos de resistência. Para obter sucesso a nível comunitário com o turismo não significa desconhecer a presença do Estado ou da mundialização do capital. Não se trata de desconectar dessas realidades, implica, contudo, em redirecionar a política estatal para os interesses das economias populares, enquanto alternativos de resultado social mais amplos e continuados. O turismo comunitário é uma estratégia de sobrevivência, e de entrada daqueles de menores condições econômicas na cadeia 
produtiva do turismo. Uma forma de turismo que pensa o lugar, a conservação ambiental e a ressignifica a cultura (CORIOLANO, 2006).

\subsection{TURISMO E PROMOÇÃO DO DESENVOLVIMENTO EM MOÇAMBIQUE: QUESTÕES BREVES}

Uma explicação geral permite compreender que o conjunto de estratégias que o governo havia adoptado tinha em vista a construção de um projeto politico e social que estava incluindo o turismo como espaço para realização do desenvolvimento local e reativar o desenvolvimento econômico, por via do turismo. Assim, Almeida (2002) sugere que como forma de efectivação do desenvolvimento, sempre houve necessidade de reafirmar um conjunto de estratégias que passam pela descentralização seja ela na sua dimensão politica, econômica e financeira. Deste modo, a estratégia de desenvolvimento de turismo em Moçambique, estava prevendo acções específicas na sua dimensão local, da qual, os atores locais participariam activamente neste processo.

Entretanto, o turismo se afigura como um elemento que tem efeitos concomitantes ou indiretos em Moçambique, sobretudo na localidade, porque, a partir dele, é possível auferir que a economia de uma determinada comunidade cresceu ou não. Os efeitos diretos do turismo podem ser percebidos por via das despesas realizadas pelos turistas dentro dos próprios equipamentos e de apoio em sua estadia e sua movimentação e os efeitos do turismo são resultantes da despesa efetuada pelos equipamentos e prestadores de serviços turísticos na compra de bens e serviços de outro tipo (BARRETTO, 1995; BARBOSA, 2005; BANDUCCI; BARRETTO, 2005).

No contexto Moçambicano, o turismo prevendo ser bem planeado, poderia permitir o surgimento de um conjunto de benefícios para o espaço no qual ocorre, com a geração de emprego, aumento de renda no local e na comunidade, promover o local, incentivar a melhoria de infraestruturas, permitir a diversificação da economia e outros aspectos adicionais. Da mesma forma, Cunha (1997, p. 32) sugere que o turismo pode contribuir no desenvolvimento local, considerando três pontos chaves: a) O desenvolvimento pode ser integrado quando o turismo surge como um promotor dominante do processo de desenvolvimento; b) $\mathrm{O}$ desenvolvimento pode ser catalítico quando as atividades turísticas surgem como estimuladoras do desenvolvimento, 
assumindo um papel complementar, e, neste caso, as atividades turísticas têm de ser compatíveis com todas as outras e; c) O desenvolvimento pode ser útil quando as atividades turísticas são úteis ao desenvolvimento regional e constituem um meio de diversificação da atividade econômica, mas não a influenciam.

Em Moçambique, considerando os postulados da Politica de Emprego, subentende-se que a partir do turismo, pretende-se expandir o investimento e diversificar a "indústria" do turismo para o aumento da renda e a promoção de emprego (PROPOSTA DE POLITICA DE EMPREGO, 2016, p. 33), e por via disso, estender as medidas activas de promoção de emprego para o sector do turismo e melhorar a qualidade da mão-de-obra e desenvolver competências para aumentar a produtividade e a competitividade nos locais de actividades turísticas.

\section{CONCLUSÕES}

Dada às constatações do debate levantado ao longo do artigo, verifica-se que a logica da sustentabilidade do turismo e suas implicações no contexto de Moçambique, seguiu uma lógica liberal, por via do ethos capitalista, segunda a qual, uma espécie de coisificação do espaço turístico em detrimento da inclusividade das demandas sociais com vista ao desenvolvimento. Nestes termos desde os anos 1980/90, verifica-se um fortalecimento do turismo seguindo a lógica dos eventos políticos, econômicos e sociais a qual se sustentava como sua ideologia e seu modus operandi.

Apesar de verificar-se em Moçambique um espaço nato de oportunidades de operações de actividades turísticas, importa referenciar que estas deveriam trabalhar de forma articulada com vista a produção de mais benesses para a comunidade local. Aliado a isso, tem se verificado que Moçambique tem uma oportunidade aberta para partilhar os benefícios económicos e sociais relacionados com o crescimento do turismo como um todo. Mas para tal, seria necessário um trabalho conjunto com os parceiros nacionais e internacionais, e a criação de ligações espaciais e temporais que se orientem a lógica do mercado.

Do mesmo modo, a tentativa de utilizar o turismo como mecanismo para a diversificação da base produtiva e crescimento da economia Moçambicana proporciona 
muitos benefícios e obviamente alguns aspectos críticos. Mas destacam-se os aspectos positivos, como (o aumento das receitas fiscais, criação de empregos, oportunidades para pequenas e médias empresas, desenvolvimento de competências, a sustentabilidade ambiental e o desenvolvimento económico local, em especial, quando os bens e serviços são produzidos localmente).

Este último ponto deve ser subentendido numa dimensão a qual, a existência de condições para se afirmar que o desenvolvimento do turismo em Moçambique pode enfrentar uma dualidade, caracterizada, pela existência de um corpo institucional e legal extenso que molda e estrutura a sua funcionalidade, ao mesmo tempo em que existe uma complexidade de simbiose entre estes elementos que culmina na criação de barreiras várias ao desenvolvimento acelerado da actividade.

\section{REFERÊNCIAS}

ACIS. Quadro legal do licenciamento de empreendimentos turísticos e afins em Moçambique. Maputo: Editora, 2008.

ALMEIDA, P. H. De. Pequena empresa e desenvolvimento local - os limites da abordagem competitiva. In: Gestão e desenvolvimento e poderes locais: marcos teóricos e avaliação. Salvador: Casa da Qualidade, 2002.

BANDUCCI, A.; J. BARRETTO, M. (Orgs.). Turismo e Identidade local. Uma visão Antropológica. Campinas: Papirus. 2001.

BARBOSA, F. O. Turismo Como um Fator de Desenvolvimento Local e/ ou Regional. Caminhos de Geografia - revista on line. 10 (14). p. 107-114. 2005.

BARRetTO, M. Manual de iniciação ao estudo do turismo. Campinas: Papirus. 1995.

BELOTTI, S. Meio Ambiente e Turismo Sustentável em Moçambique: Organização Territorial e Conhecimentos Culturais no Parque Nacional de Zinave. ATAS DO CONGRESSO INTERNACIONAL SABER TROPICAL EM MOÇAMBIQUE: HISTÓRIA, MEMÓRIA E CIÊNCIA - IICT - JBT/Jardim Botânico Tropical. Lisboa, 24-26 outubro. Lisboa: Instituto de Investigação Científica Tropical, 2012.

BENI, M. C. Análise estrutural do turismo. 10. ed. São Paulo: Editora Senac, 2007. 
CISTAC, G.; EDUARDO, C. (eds.) Turismo e desenvolvimento local. Universidade Eduardo Mondlane, Faculdade de Direito, Núcleo de Estudos Sobre a Administração Pública e o Desenvolvimento Local, 2007.

CRUZ, R. C. A. O Nordeste que o turismo (ta) não vê. ln: RODRIGUES, A. B. Turismo. Modernidade. Globalização. São Paulo: Hucitec, 2001.

CHESNAIS, F. A mundialização do capital. São Paulo: Xamã,1996.

CORIOLANO, L. N. Turismo: prática social de apropriação e de dominação de territórios. En publicación: América Latina: cidade, campo e turismo. Amalia Inés Geraiges de Lemos, Mónica Arroyo, María Laura Silveira. CLACSO, Consejo Latinoamericano de Ciencias Sociales, San Pablo. Diciembre. 2006.

Turismo de inclusão e desenvolvimento local. Fortaleza: FUNECE, 2003.

CUNHA, L. Economia e Política do Turismo. Portugal: McGraw’Hill, 1997.

DECRETO 77 DE 2009. Zonas de Interesse Turístico. Maputo. Moçambique, 2009.

DECRETO N. ${ }^{\circ}$ 97/2013. Regulamento de Empreendimentos Turísticos, Restauração e Bebidas e Salas de Dança. Maputo, Moçambique, 2013.

DOMINGOS, C. T. Políticas públicas de promoção turística e desenvolvimento sustentável: um estudo de caso em Vilankulos/Moçambique. Dissertação de Mestrado. (Administração de Organizações). Faculdade de Economia, Administração e Contabilidade de Ribeirão Preto. Universidade de São Paulo, Ribeirão Preto, 2012.

FERNANDO, M.; GONÇALVES, A. Vulnerabilidade socio-ambiental das políticas de desenvolvimento do turismo em Moçambique: a experiencia das "Áreas Prioritárias para o Investimento Turístico - APIT's" em Inhambane. XIV ENCONTRO DA REDE LUSO-BRASILEIRA DE ESTUDOS AMBIENTAIS, 2011.

FURTADO, C. O capitalismo global. 2. ed. São Paulo: Paz e Terra, 1998.

GOVERNO DE MOÇAMBIQUE. Lei de turismo. Maputo, Moçambique, 2004.

HARVEY, D. O Neoliberalismo: História e Implicações. São Paulo: Loyola, 2008.

IANNI, O. Nação: província da sociedade global. In: SANTOS, M.; SOUZA, M. A. de; SILVEIRA, M. L. Território: globalização e fragmentação. 4 (2002): p. 77-84.

Território globalização e fragmentação. 2. ed. São Paulo: Hucitec. 1996.

JONES, S.; IBRAHIMO, H.; MATOS, C.; NEVES, H.; NHAMPOSSA, P. Turismo e a economia local: o caso da Praia do Bilene, Moçambique. Documento para discussão número 56. Bilene, Moçambique, 2007. 
LAGE, B. H. G. Economia do Turismo. 7. ed. São Paulo: Atlas. 2001.

LEI DO TURISMO DE MOÇAMBIQUE. Lei $n^{\circ}$ 4/2004, de 17 de Junho. Maputo, Moçambique. 2004.

MACAMO, M. S. Ecoturismo e desenvolvimento local. Reserva especial de Maputo-Moçambique. 2014. Tese de Doutorado. Instituto Universitário da MaiaISMAI, 2014. Reserva especial de Maputo-Moçambique. Disponível em: <https://repositorio.ismai.pt/handle/10400.24/260?mode=full>.

MENEZES, F. O. de. O município de Bodoquena-MS: uma análise do turismo como instrumento de auxílio para o desenvolvimento local. Dissertação (Mestrado em Desenvolvimento Local) - Universidade Católica Dom Bosco, Programa de PósGraduação em Desenvolvimento Local, Campo Grande-MS, 2004.

MINISTÉRIO DO TRABALHO, EMPREGO E SEGURANÇA SOCIAL PROPOSTA DE POLÍTICA DE EMPREGO Promovendo mais e melhores empregos em Moçambique. Maputo, Maio, 2016.

MINISTÉRIO DO TURISMO. Parque Nacional de Zinave, Plano de Acção Comunitária. Maputo: Ministério do Turismo, Moçambique, 2010.

MITUR, Ministério do Turismo de Moçambique. Moçambique, 2006.

MORAES, L. A. de; GÂNDARA, J. M. G. Midiatização e Espetacularização do Turismo. Turismo e Sociedade. Curitiba, v. 9, n. 1, p. 1-18, 2016.

OMT - ORGANIZAÇÃO MUNDIAL DO TURISMO. International Tourist Arrivals by Country of Destination. 2016.

PEARCE, D. Tourism Today - A Geographical Analysis. New York: Longman, 1991.

PLANO ESTRATÉGICO PARA DESENVOLVIMENTO DO TURISMO EM MOÇAMBIQUE I (2004-2013) Aprovada na 15 ${ }^{\text {a }}$ Sessão Ordinária de Conselho de Ministros. Maputo. 2004, e II (2016-2025) aprovado em Dezembro, 2015. Maputo, Moçambique, 2015.

POLÍTICA DO TURISMO E ESTRATÉGIA DA SUA IMPLEMENTAÇÃO. Maputo, Moçambique. Abril de 2003.

PRODANOV, C. C.; FREITAS, E. C. de. Metodologia do trabalho científico. Novo Hamburgo: Feevale. 2009.

REGULAMENTO DE ANIMAÇÃO TURISTICA. Conselho de Ministros. Maputo, Moçambique. 2007. 
REPÚBLICA DE MOÇAMBIQUE. Plano Estratégico para o Desenvolvimento do Turismo em Moçambique, 2004-2013. (2004).

RICHARDSON, R. J. Pesquisa social: métodos e técnicas. 3. ed. São Paulo: Atlas, 1999.

RODRIGUES, A. B. Turismo e Espaço. Rumo a um conhecimento transdisciplinar. São Paulo: HUCITEC, 1997.

RUSCHMAN, D. V. M. Turismo e Planeamento Sustentável: A protecção do meio ambiente. 5. ed. Campinas, S. Paulo: Papirus Editora, 1999.

SANTOS. M. Técnica espaço tempo: globalização e meio técnico científico informacional. 2. ed. São Paulo: Hucitec, 1996.

SILVA, L. F. da; MANTOVANElI JÚNIOR, O; SAMPAIO, C. A. C. Desenvolvimento turístico regional: Governança e territorialidade no caso da Oktoberfest Blumenau (Santa Catarina, Brasil). Turismo e Sociedade. Curitiba, v. 7, n. 1, p. 156-173, jan. 2014.

SILVEIRA, M. A. T. da. Turismo, políticas de ordenamento territorial e desenvolvimento. Um foco no estado do Paraná no contexto regional. 277. Tese (Doutorado em Geografia) Faculdade de Filosofia, Letras, Ciências Humanas, Universidade de São Paulo - USP, São Paulo, 2002.

TORRES, C. A nova legislação do turismo de Moçambique. TURISVER, XX (647). Universidade de São Paulo, 2012.

VALENTE, T. P.; MIELKE, E. J. C. Evolução e Potencialidades de Inovação do Turismo de Base Comunitária no Município de Guaraqueçaba - PR (Brasil). Turismo e Sociedade. Curitiba, v. 10, n. 3, p. 1-26, Janeiro de 2018.

ZIMMERMANN, A. Planejamento e organização do turismo rural no Brasil. In: ZIMMERMANN, A.; CASTRO, I. Turismo rural - um modelo brasileiro. Florianópolis: Ed. do Autor, 1996.

Recebido em: 26-03-2018.

Aprovado em: 25-04-2018.

Versão aprovada para publicação: 09-12-2018. 